\title{
NGHIÊN CƯU NÂNG CAO KỸ NĂNG GIAO TIẾP VỚI NGƯỜI NƯỚC NGOÀI CHO SINH VIÊN KHỐI NGÀNH CÔNG NGHỆ Phan Hoàng Danh ${ }^{(*)}$
}

(*) Thạc sĩ. Truòng Đại học Công nghệ Đồng Nai. Email: phanhoangdanh@dntu.edu.vn

DOI: $10.37550 /$ tdmu.CFR/2021.01.126

\section{Tóm tắt}

Theo nhũng tiêu chuẩn về chuơng trình CDIO (tiêu chuẩn 3:1 và 3:2) quy định sụ cần thiết để tập trung vào xây dụng đội ngũ nhóm và kỹ năng giao tiếp cho người học. Trong đó việc chuẩn hóa giáo dục trong kỹ thuật sẽ bổ sung thêm nhũng kỹ năng cần thiết trong giao tiếp. Dựa vào nhũng khía cạnh hiệu quả mang lại tù chuơng trình, truò̀ng Đại hoc Công nghệ Đồng Nai (DNTU) đang nghiên cưu để áp dụng tiêu chuẩn CDIO mới để quốc tế hóa môi truòng giáo dục tại DNTU. Các công ty hợp tác với DNTU cũng đề xuất sinh viên tốt nghiệp phải có kỹ năng giao tiếp với người nước ngoài để có nhiều co hội việc làm cho các công ty nước ngoài. Mục đích của nghiên cưu này là để phân biệt các yếu tố văn hóa tù các đất nước, vùng miền khác nhau ảnh hương đến hiệu quả làm việc nhóm của sinh viên để tù đó nhận ra các vấn đề và các yếu tố ảnh hương đến giao tiếp đa văn hóa mà sinh viên gặp phải. Kết quả của nghiên cúu sẽ là tài liệu hũu ich cho việc áp dụng chuơng trình CDIO 3:1 và 3:2 tại DNTU.

Tù khóa: Xây dưng nhóm, giao tiếp đa văn hóa, kỹ năng giao tiếp với người nước ngoài

\section{1. Đặt vấn đề}

Một sinh viên DNTU thuộc khoa công nghệ, khối ngành ô tô đứng lên tại thời điểm đánh giá cuối cùng khóa học “ kỹ năng giao tiếp đa văn hóa” để đưa ra một số nhận định và phản hồi về công việc của nhóm trong sáu tuần qua. Anh ấy giới thiệu về quá trình thiết kế khuôn đúc bằng sử dụng phần mềm $3 \mathrm{D}$ solidworks bằng tiếng Anh và bằng tiếng Hàn, nội dung trình bày khá phong phú và các thách thức khi làm việc nhóm và giao tiếp tiếng Anh cũng như tiếng Hàn với một nhóm sinh viên người Hàn qua thực tập và tham gia vào khóa học "kỹ năng giao tiếp đa văn hóa" anh ấy nói rằng khóa học và làm việc nhóm đã giúp anh ấy nhận ra rằng kỹ năng giao tiếp đa văn hóa cực kỳ quan trọng trong công việc, đặc biệt là các công việc bắt buộc phải làm theo nhóm, việc nâng cao kỹ năng này sẽ giúp công việc diễn ra một cách nhanh chóng và hiệu quả hơn. 


\section{Sự cần thiết}

Trường Đại học Công nghệ Đồng Nai, là một trường đại học với số lượng sinh viên tốt nghiệp mỗi năm chuyên ngành kỹ thuật lên tới 500 sinh viên, nguồn sinh viên này đáp ứng nhu cầu cho các khu công nghiệp xung quanh như AMATA, Long Bình, Bàu Xéo, Biên Hòa I, Biên Hòa II. Sự cần thiết phải nâng cao kỹ năng giao tiếp với người nước ngoài để đáp ứng số lượng lớn các công ty là điều cấp thiết. Các công ty hợp tác, mong muốn tăng cường khả năng thích ứng văn hóa cho cả sinh viên trao đổi khi đi thực tập thực tế tại doanh nghiệp và sự cần thiết của các kỹ năng làm việc nhóm trôi chảy giữa các sinh viên trong chương trình đào tạo tại DNTU. Trường Đại học Công nghệ Đồng Nai muốn đảm nhận vai trò hàng đầu, tiên phong trong nước liên quan đến nghiên cứu, phát triển và phổ biến công nghệ mới nhằm tăng cường năng lực cạnh tranh quốc tế của các đại học. Các công ty nước ngoài tại các khu công nghiệp xung quanh DNTU làm việc trên thị trường toàn cầu và cần kỹ sư với kinh nghiệm quốc tế, bao gồm các kỹ năng ngôn ngữ và đa văn hóa. Các doanh nghiệp vừa và nhỏ ở khu công nghiệp Biên Hòa thường có các nhà thầu phụ hoặc thậm chí sản xuất của chính họ ở nước ngoài và do đó tìm kiếm kỹ sư trẻ có năng lực quốc tế là mục tiêu quan trọng để nâng cao sức cạnh tranh của họ. DNTU đã giới thiệu nhiều công ty và học bổng tại nước ngoài cho sinh viên, khuyến khích cho sinh viên tham gia trao đổi quốc tế và tìm kiếm thỏa thuận hợp tác với các trường đại học trên thế giới tạo điều kiện trao đổi sinh viên. Do đó, khoảng $15 \%$ sinh viên tốt nghiệp DNTU đã tham gia vào một chương trình trao đổi học tiếp lên thạc sỹ tại các nước như Hàn Quốc, Nhật Bản, Úc. Nếu sinh viên không có kỹ năng giao tiếp đa văn hóa sẽ bị sốc văn hóa và trở nên mất tự tin dẫn đến phụ thuộc vào sinh viên quốc tế hoặc thậm chí từ bỏ chương trình học và trở về nhà. Đào tạo nâng cao kỹ năng giao tiếp với người nước ngoài thường dựa trên các dự án nhóm trong đó kỹ năng làm việc nhóm là cốt yếu. Tin rằng nhóm làm việc đa văn hóa mang lại một môi trường để đổi mới và tư duy sáng tạo, DNTU đang nghiên cứu để áp dụng kỹ năng làm việc nhóm đa văn hóa, nâng cao năng lực giao tiếp với người nước ngoài phù hợp với tiêu chuẩn CDIO 3:1 và CDIO 3:2.

\section{Kết quả}

Bài nghiên cứu đề cập đến sự khác nhau về vùng miền, khác nhau về ngôn ngữ. Giống như tất cả con người, ai cũng tò mò về những điều mới mẻ như văn hóa hoặc con người. Nhận ra sự tò mò này, các cá nhân có thể được khuyến khích để nỗ lực giao lưu với các cá nhân từ các vùng văn hóa khác. Nhận thức về điều này có thể làm giảm sự căng thẳng của giai đoạn thích ứng và ảnh hưởng của sốc văn hóa cho các bạn sinh viên khi mới bước vào ngưỡng cửa đại học, xa nhà, xa gia đình và gặp gỡ với các bạn sinh viên từ các tỉnh khác, vùng miền văn hóa khác. Bài nghiên cứu đưa ra các nhóm để so sánh về các khó khăn cũng như tìm ra các phương án tối ưu nhất để áp dụng tiêu chuẩn CDIO.

Nhóm 1: Sau khi thảo luận về rào cản ngôn ngữ "Là những sinh viên quốc tế và sinh viên DNTU khi tham gia khóa học kỹ năng giao tiếp đa văn hóa” đó là một trải nghiệm thú vị. Ban đầu, mọi người rất hào hứng khi các nhóm được xây dựng vì đây là môi trường đa văn hóa quan trọng đầu tiên đối với hầu hết sinh viên. Sau đó, quen nhau, mọi người ngày 
càng thoải mái và nói chuyện nhiều hơn. Học hỏi những điều mới về các nền văn hóa khác và lắng nghe ý kiến của mọi người về nền văn hóa của chúng ta rất xuất sắc. Khi chúng tôi bắt đầu quen nhau, những bài phát biểu trở nên chân thành hơn. Với sự giúp đỡ của những cuộc trò chuyện chân thành, chúng tôi đã khám phá ra những vấn đề mà chúng tôi đã phải đối mặt trong quá trình giao tiếp trước đây, và nâng cao khả năng giao tiếp với ngôn ngữ quốc tế là tiếng Anh.

Nhóm 2: Nhóm bao gồm bốn quốc tịch ( Hàn, Nhật, Úc, Việt Nam) đã so sánh các vấn đề liên quan đến thành kiến và khó khăn của việc tạo ra các mối quan hệ mới. Họ đưa ra lời khuyên sau đây cho DNTU "Vì mọi người từ các quốc tịch khác nhau có xu hướng làm việc theo nhóm khác nhau bởi vấn đề không hiểu ngôn ngữ đối phương", chúng tôi nghĩ rằng các giáo viên ở trường có thể tạo các nhóm với các quốc tịch khác nhau khi lớp học đang có một buổi học trong phòng thí nghiệm chẳng hạn. Điều này buộc mọi người phải tìm hiểu để biết nhau và làm việc với nhau. Điều này cũng giúp các sinh viên quốc tế để tìm hiểu thêm về văn hóa Việt Nam và cách sống của người Việt Nam.

Nhóm 3: Sinh viên thường đối mặt với một vấn đề mà mọi người đều gặp phải là cư xử định kiến với họ. Nó xảy ra ngay cả giữa sinh viên nước ngoài sinh viên DNTU hoặc ngay cả các sinh viên DNTU giữa các tỉnh thành khác nhau. Các sinh viên nước ngoài tụ tập thành các nhóm gần gũi và ngại cho người nước khác vào.

Nhóm 4: Thảo luận về vai trò của ngôn ngữ cơ thể trong bối cảnh giao tiếp đa văn hóa, bài luận đưa ra điều này có liên quan thí dụ: Ở một số vùng của Ấn Độ, việc nhìn thẳng vào cha mẹ của bạn, được coi là thiếu tôn trọng nhưng cùng một lúc điều này ở các nước khác lại ngược lại, chúng ta nên nhìn nhau khi trò chuyện để thể hiện sự tôn trọng.

Nhóm 5: Sau khi thảo luận về các cuộc gặp gỡ giữa các nền văn hóa cả trong và ngoài khuôn viên trường, bài luận đưa ra những điều sau kết luận phản ánh về khóa học này và công việc nhóm đóng vai trò quan trọng trong đó không chỉ mang lại cho chúng tôi kiến thức mới và hiểu biết sâu rộng về các nền văn hóa mới, nó cũng đã là một phần quan trọng trong việc tạo ra những người bạn mới từ khắp nơi trên thế giới. Đây có lẽ là một trong những những lý do lớn nhất đối với toàn bộ khóa học. Bằng cách hoạt động lắng nghe và hiểu các nền văn hóa, truyền thống và giá trị khác, tất cả chúng ta đã học được cách nhìn mới về mọi người. Hơn nữa, chúng tôi cũng đã học cách tránh rập khuôn, hiệu quả giao tiếp bằng cách tiếp cận thân thiện và cách tôn trọng người khác.

\section{Kết luận}

Khi lãnh đạo trường Đại học Công nghệ Đồng Nai họp để thảo luận về việc chuẩn hóa giáo dục trong kỹ thuật đã bổ sung thêm những kỹ năng cần thiết trong việc nâng cao kỹ năng giao tiếp với người nước ngoài. Với kết quả thu được và sau khi đánh giá ba lần liên tiếp các khóa học, việc đầu tư thời gian vào đào tạo đa văn hóa tại DNTU đã được chứng minh là mang lại hiệu quả thiết thực cho sinh viên sau khi tốt nghiệp, đáp ứng được yêu cầu từ các công ty, đặc biệt là các công ty nước ngoài nơi mà hầu như phải giao tiếp và làm việc bằng ngôn ngữ thứ hai (tiếng Anh, tiếng Nhật, tiếng Hàn...). Việc nâng cao kỹ năng giao tiếp với người nước ngoài trong chương trình học tạo ra một môi trường học tập 
hài hòa và nhân văn hơn, phù hợp với mục tiêu của $\mathrm{CDIO}$ là hướng tới việc giúp sinh viên có được kỹ năng cứng và mềm cần thiết khi ra trường, nhằm đáp ứng yêu cầu, đòi hỏi của của xã hội và hội nhập quốc tế về giáo dục kỹ thuật toàn diện.

\section{Tài liệu tham khảo}

[1] Brewster, Tom and Elizabeth S. Brewster. (1976). Language Acquisition Made Practical (LAMP): Field methods for language learners. Colorado Springs: Lingua House.

[2] Campbell, Duncan. "Proposed new CDIO Standard (13), CDIO Program Internationalization and Mobility”. CDIO Submission. Queensland University of Technology ( 2009).

[3] Hofstede, Greet. (2001). Culture's consequences: Comparing values, behaviours, institutions, and organizations across nations (2nd ed.). Thousand Oaks, CA: Sage Publications.

[4] Hofstede, Geert. Hofstede Gert-Jan. (2004) Cultures and Organisations: Software for the mind. Maidenhead: McGraw-Hill.

[5] Jandt, Fred E. (2007) An Introduction to Intercultural Communication - Identities in a Global Community. London: Sage Publications. 